\title{
The domestic cat as a natural animal model of Alzheimer's disease
}

\author{
James K. Chambers ${ }^{1}$, Takahiko Tokuda ${ }^{2,3}$, Kazuyuki Uchida ${ }^{1 *}$, Ryotaro Ishii ${ }^{3}$, Harutsugu Tatebe ${ }^{3}$, Erika Takahashi ${ }^{4}$, \\ Takami Tomiyama $^{5^{*}}$, Yumi Une ${ }^{4}$ and Hiroyuki Nakayama ${ }^{1}$
}

\begin{abstract}
Introduction: Alzheimer's disease (AD) is the most dominant neurodegenerative disorder that causes dementia, and no effective treatments are available. To study its pathogenesis and develop therapeutics, animal models representing its pathologies are needed. Although many animal species develop senile plaques (SP) composed of amyloid- $\beta$ (A $\beta$ ) proteins that are identical to those found in humans, none of them exhibit neurofibrillary tangles (NFT) and subsequent neurodegeneration, which are integral parts of the pathology of AD.
\end{abstract}

Results: The present study shows that $A \beta$ accumulation, NFT formation, and significant neuronal loss all emerge naturally in the hippocampi of aged domestic cats. The NFT that form in the cat brain are identical to those seen in human $\mathrm{AD}$ in terms of their spatial distribution, the cells they affect, and the tau isoforms that comprise them. Interestingly, aged cats do not develop mature argyrophilic SP, but instead accumulate intraneuronal A $\beta$ oligomers in their hippocampal pyramidal cells, which might be due to the amino acid sequence of felid $A \beta$.

Conclusions: These results suggest that A oligomers are more important than SP for NFT formation and the subsequent neurodegeneration. The domestic cat is a unique animal species that naturally replicates various $A D$ pathologies, especially A $\beta$ oligomer accumulation, NFT formation, and neuronal loss.

Keywords: Alzheimer's disease (AD), Amyloid $\beta(A \beta)$, Cat, Neurodegeneration, Oligomer, Tau

\section{Introduction}

Alzheimer's disease (AD) is a neurodegenerative disorder characterized by three major pathologies: senile plaques (SPs), neurofibrillary tangles (NFTs), and neuronal loss. The former two are extracellular and intracellular argyrophilic aggregates composed of amyloid $\beta$ (A $\beta)$ and hyperphosphorylated tau protein, respectively. Accumulating evidence indicates that $A \beta$ accumulation leads to NFT formation and subsequent neuronal loss and cognitive dysfunction [24, 29, 47]. Based on this notion, various transgenic $(\mathrm{Tg})$ mouse models have been generated by introducing human APP (amyloid precursor protein) or PSEN (presenilin) with the mutations linked to familial $\mathrm{AD}$ [23]. These Tg mice produce human $\mathrm{A} \beta$ beyond physiological levels, leading to massive formation of

\footnotetext{
*Correspondence: auchidak@mail.ecc.u-tokyo.ac.jp; tomi@med.osaka-cu.ac.jp 'Department of Veterinary Pathology, Graduate School of Agricultural and Life Sciences, The University of Tokyo, Tokyo, Japan

${ }^{5}$ Department of Neuroscience, Osaka City University Graduate School of Medicine, Osaka, Japan

Full list of author information is available at the end of the article
}

SPs [13]. Nevertheless, they fail to develop NFTs and neuronal loss unless mutant MAPT (tau) is simultaneously introduced. Although wild-type mice do not spontaneously form SPs or NFTs, many other animal species such as monkeys and dogs are known to develop SPs as they age $[19,25,44,48,58]$. However, these animals do not display NFTs and neuronal loss. If an animal species can be identified that naturally develops SPs, NFTs, and neuronal loss, it could be a desirable animal model for translational studies of AD. Hyperphosphorylated tau (AT8-positive) has been observed in the brains of domestic cats with signs of neurological dysfunction $[18,26]$. Furthermore, recently, we found that aged leopard cats and cheetahs display both $A \beta$ deposits and NFTs in the brains $[8,49]$. Leopard cats and cheetahs are endangered wild animals, thus they are not adequate for further laboratory examination. In contrast, domestic cats, which diverged from a common ancestor with the leopard cat and cheetah approximately 6.2 million years ago [32], could be used in such studies if they produce $A \beta$ deposits and NFT. Here, we report that aged domestic cats naturally 
accumulate $A \beta$ oligomers, produce NFT, and moreover suffer hippocampal neuronal loss, and thus, could serve as a valuable animal model of human $\mathrm{AD}$.

\section{Materials and methods Brain samples}

Cat brain tissues of various ages were examined (Table 1). All the adult cat brains were obtained through routine necropsies performed at the Department of Veterinary Pathology, the University of Tokyo. The fetal brain samples were purchased from a laboratory animal supplier (Nisseiken Co. Ltd., Tokyo, Japan). All procedures were done according to the institutional regulations for animal research. One hemisphere of the brain was fixed in $10 \%$ phosphate-buffered formalin, and the other hemisphere was coronally sectioned and then frozen at $-80{ }^{\circ} \mathrm{C}$ until use.

Table 1 Age, sex and immunohistochemical results for A 342 and hyperphosphorylated tau in cats

\begin{tabular}{|c|c|c|c|c|}
\hline No. & Age & Sex & $A \beta 42$ & HP-tau \\
\hline 1 & fetus (50 days) & $\mathrm{F}$ & - & $+^{a}$ \\
\hline 2 & fetus (50 days) & M & - & $t^{a}$ \\
\hline 3 & 2-week-old & $\mathrm{F}$ & - & - \\
\hline 4 & 2-week-old & $\mathrm{F}$ & - & - \\
\hline 5 & 3-year-old & M & - & - \\
\hline 6 & 3-year-old & M & - & - \\
\hline 7 & 4-year-old & $\mathrm{F}$ & - & - \\
\hline 8 & 4-year-old & $\mathrm{F}$ & - & - \\
\hline 9 & 5-year-old & $\mathrm{F}$ & - & - \\
\hline 10 & 8-year-old & $\mathrm{F}$ & + & - \\
\hline 11 & 14-year-old & $\mathrm{F}$ & - & - \\
\hline 12 & 14-year-old & M & + & ++ \\
\hline 13 & 15-year-old & $\mathrm{F}$ & + & + \\
\hline 14 & 15-year-old & M & + & - \\
\hline 15 & 15-year-old & ND & + & - \\
\hline 16 & 16-year-old & $\mathrm{F}$ & + & - \\
\hline 17 & 16-year-old & M & + & - \\
\hline 18 & 17-year-old & $\mathrm{F}$ & + & - \\
\hline 19 & 17-year-old & $\mathrm{F}$ & + & + \\
\hline 20 & 17-year-old & ND & + & + \\
\hline 21 & 18-year-old & $\mathrm{F}$ & + & + \\
\hline 22 & 19-year-old & $\mathrm{F}$ & + & ++ \\
\hline 23 & 20-year-old & $\mathrm{F}$ & + & + \\
\hline 24 & 20-year-old & ND & + & ++ \\
\hline 25 & 22-year-old & M & + & + \\
\hline
\end{tabular}

$A \beta 42$ : -, negative; +, small aggregates of $A \beta 42$ were observed in the parietal and temporal cortices on FA-pretreated sections, and intracellular aggregates of $A \beta 42$ were observed in the cytoplasm of hippocampal pyramidal cells. HP-tau: -, negative; +, AT8-positive cells limited to the entorhinal cortex; ++, AT8-positive cells in the entorhinal cortex and throughout the hippocampus. F, female; M; male, ND, no data; ${ }^{\text {a }}$, weak AT8 positivity on the surface of cerebral cortex

\section{Histology}

Formalin fixed paraffin-embedded tissues were cut into 4$\mu \mathrm{m}$-thick serial sections. The deparaffinized sections were then stained with HE, periodic acid-methenamine silver, Congo red and the Gallyas-Braak method. Digital images were obtained using an Olympus BX 50 microscope (Olympus, Tokyo, Japan) equipped with a Nikon DS-Ri1 digital camera (Nikon, Tokyo, Japan).

\section{Immunohistochemistry}

Consecutive sections were stained using the immunoenzyme technique. Sections were deparaffinized and rehydrated. Antigen retrieval was done by heating or with FA (for $A \beta$ ). The sections were immersed in $1 \%$ hydrogen peroxide in methanol for $20 \mathrm{~min}$ in order to deactivate endogenous peroxidases, and then immersed in $5 \%$ skim milk in Tris-buffered saline (TBS) in order to avoid nonspecific binding of the antibody. The following primary antibodies were used: mouse antihyperphosphorylated-tau Ser202/Thr205 (clone AT8, 1:100, Thermo Scientific, Rockford, IL), mouse antihyperphosphorylated-tau Ser212/Thr214 (clone AT100, 1:100, Thermo Scientific), mouse anti-3-repeat-tau RD3 (clone 8E6/C11, 1:100, Millipore, Temecula, CA), mouse anti-4-repeat-tau RD4 (clone 1E1/A6, 1:100, Millipore), rabbit anti-pan-tau (1:100, Sigma, St. Louis, MO), mouse anti-A $\beta 42$ (clone $12 \mathrm{~F} 4,1: 1000$, Millipore), rabbit antiA $\beta 42$ (1:1000, IBL, Gunma, Japan), rabbit anti-A $\beta N 1$ (1:100, IBL), rabbit anti-A $\beta \mathrm{pN} 3$ (1:100, IBL), rabbit antiUbiquitin (1:200, Dako, Carpinteria, CA), rabbit antiApolipoprotein (Apo) E (A299, 1:100, IBL), and mouse anti-NeuN (clone A60, 1:100, Millipore). After incubation with each primary antibody at $4{ }^{\circ} \mathrm{C}$ overnight, immunolabeled antigens were visualized using the Dako Envision + System (Dako). In brief, the sections were incubated with the secondary antibody linked to a peroxidase-conjugated polymer backbone at $37^{\circ} \mathrm{C}$ for $40 \mathrm{~min}$, reacted with $0.05 \%$ 3'3-diaminobenzidine plus $0.03 \%$ hydrogen peroxide in Tris-hydrochloric acid buffer, and then counterstained with hematoxylin. Negative controls were obtained by omitting the primary antibodies. Neuronal loss in the pyramidal cell layer of the hippocampal CA1 region was evaluated by counting NeuN-positive cells displayed in Fig. 6a. Comparisons of the means among the three groups were performed with one-way ANOVA followed by Tukey's HSD test using SPSS software (IBM, Tokyo, Japan). Differences with a $P$ value of $<0.05$ were considered significant.

\section{Double-labeling immunofluorescence}

Sections were deparaffinized and rehydrated. Antigen retrieval was done by heating. In order to reduce autofluorescence, Sudan black B treatment was performed. Sections were immersed in $5 \%$ skim milk in TBS. After 
incubation with each of the primary antibodies at $4{ }^{\circ} \mathrm{C}$ overnight, the sections were washed with TBS. The sections were then incubated with corresponding secondary antibodies at $37{ }^{\circ} \mathrm{C}$ for $1 \mathrm{~h}$, mounted with Vectashield (H-1500, Vector Laboratories, Burlingame, CA), and examined under a Leica DMI 3000B fluorescence microscope (Leica Microsystems, Tokyo, Japan) or a Carl Zeiss LSM700 Confocal Laser Scanning Microscopy (Carl Zeiss, Tokyo, Japan). Primary antibodies used were as follows: mouse anti-hyperphosphorylated-tau Ser202/Thr205 (clone AT8, 1:100, Thermo Scientific), rabbit anti-MAP2 (1:1000, Millipore), rabbit anti-GFAP (1:400, Dako), rabbit anti-Olig2 (1:200, Millipore), mouse anti-RAB9 (clone Mab9, 1:100, LSBio, Seattle, WA), and rabbit anti-A $\beta 42$ (1:100, IBL). Secondary antibodies used were as follows: ALEXA594-conjugated goat anti-mouse IgG (1:100, Invitrogen, Eugene, OR), ALEXA488-conjugated goat anti-rabbit IgG (1:100, Life Technologies, Eugene, OR), ALEXA594-conjugated goat anti-rabbit IgG (1:100, Life Technologies), and ALEXA488-conjugated goat antimouse IgG (1:100, Invitrogen).

\section{Transmission electron microscopy}

Formalin fixed hippocampal tissues with NFTs (confirmed by Gallyas-Braak method) were cut into $1-\mathrm{mm}$ cubes and then post-fixed with $2 \%$ osmium oxide in phosphate buffer $(100 \mathrm{mM}, \mathrm{pH} 7.2)$ at $4{ }^{\circ} \mathrm{C}$ for $1 \mathrm{~h}$. After washed in phosphate buffer, the tissues were dehydrated in a graded series of ethanol, displaced by propylene oxide and then embedded in Spurr resin (Spurr Low Viscosity Embedding Kit, Polysciences, Warrington, PA). Ultrathin sections (70-nm-thick) were stained with $4 \%$ uranyl acetate in distilled water and Reynolds' lead citrate, and then examined with a JEM-1010 transmission electron microscope (JEOL, Tokyo, Japan).

\section{Protein extraction}

For tau extraction, hippocampal tissues were homogenized in four volumes of TBS containing a protease inhibitor cocktail (cOmplete Mini, Roche, Mannheim, Germany) and a phosphatase inhibitor cocktail (PhosSTOP, Roche) and fractioned by three-step ultracentrifugation including TBS, sarkosyl (sodium $\mathrm{N}$-dodecanoylsarcosinate) and guanidine hydrochloride ( $\mathrm{GuHCl}$ ) extraction, essentially as described previously [21]. For the dephosphorelation assay, phosphatase inhibitor cocktail was omitted. In brief, the homogenates were centrifuged at $125,000 \times g$ at $4{ }^{\circ} \mathrm{C}$ for $1 \mathrm{~h}$, and the supernatants were harvested as TBS-soluble fractions. The precipitates were dissolved by sonication in four volumes of $1 \%$ sarkosyl in TBS containing the protease inhibitor cocktail and the phosphatase inhibitor cocktail, and then the solutions were incubated at room temperature (RT) for $1 \mathrm{~h}$. After centrifugation at $125,000 \times g$ at RT for $15 \mathrm{~min}$, the supernatants were removed. The sarkosyl- insoluble precipitates were then dissolved by sonication in two volumes of $4 \mathrm{~mol} / \mathrm{L} \mathrm{GuHCl}$ and incubated at RT for $1 \mathrm{~h}$. After a second centrifugation at $125,000 \times g$ at RT for $15 \mathrm{~min}$, the supernatants were harvested, and the solvent $(4 \mathrm{~mol} / \mathrm{L} \mathrm{GuHCl}$ ) was exchanged with TBS containing the protease inhibitor cocktail and the phosphatase inhibitor cocktail using Amicon Ultra $10 \mathrm{~K}$ filter devices (Millipore).

For $A \beta$ extraction, hippocampal and parietal cortex tissues were homogenized in four volumes of TBS containing the protease inhibitor cocktail and fractioned by three-step ultracentrifugation including TBS, SDS, and FA extraction. In brief, the homogenates were centrifuged at $100,000 \times g$ at $4{ }^{\circ} \mathrm{C}$ for $1 \mathrm{~h}$, and the supernatants were harvested as TBS fractions. The precipitates were dissolved in four volumes of $2 \%$ SDS in TBS containing the protease inhibitor cocktail, centrifuged at $100,000 \times g$ at RT for $1 \mathrm{~h}$, and the supernatants were harvested as SDS fractions. The precipitates were finally dissolved in $70 \%$ FA in water. After centrifugation at $100,000 \times g$ at RT for $1 \mathrm{~h}$, the supernatants were harvested as FA fractions. The TBS and SDS fractions were diluted 10- and 20-fold, respectively, in TBS containing the protease inhibitor cocktail, and the FA fractions were neutralized by 1:10 dilution into $1 \mathrm{M}$ Tris solution, $\mathrm{pH}$ 11. The protein concentrations of the resultant solutions were determined by the BCA protein assay (Thermo Scientific).

\section{Western blotting}

For tau analysis, extracts of the hippocampus were incubated with alkaline phosphatase mix $(500 \mathrm{mM}$ Tris- $\mathrm{HCl}$ $\mathrm{pH}$ 9.0, $500 \mathrm{mM} \mathrm{MgCl} 2,0.1 \mathrm{M}$ DTT (Invitrogen), 10,000U/ $\mathrm{ml}$ calf intestinal alkaline phosphatase (New England Biolabs, Ipswich, MA)) at $37{ }^{\circ} \mathrm{C}$ overnight for dephosphorylation. Subsequently, aliquots (5 $\mu$ g protein) were electrophoresed on 4-12\% Bolt Bis-Tris Plus gel (Thermo Fisher Scientific, Waltham, MA) and transferred to 0.45$\mu \mathrm{m}$ PVDF membranes (Millipore). Nonspecific binding was blocked with $5 \%$ skim milk in TBS containing Tween 20 (TBS-T, $20 \mathrm{mM}$ Tris- $\mathrm{HCl}$ buffer, $\mathrm{pH}$ 7.0, containing $50 \mathrm{mM} \mathrm{NaCl}$ and $0.1 \%$ Tween 20) for $30 \mathrm{~min}$. The following primary antibodies were used: mouse anti-tau (clone TAU-5, 1:1000, Life Technologies), RD3 (clone 8E6/C11, 1:1000, Millipore), and RD4 (clone 1E1/A6, 1:1000, Millipore). Alkaline phosphatase-conjugated antimouse IgG was then applied. The blotting signals were visualized with 5-bromo-4-chloro-3'-indolylphosphatase p-toluidine salt/nitro-blue tetrazolium chloride (BCIP/ NBT) and imaged with an Image Quant LAS $4000 \mathrm{mini}$ bio-molecular imager (GE Healthcare Bio-Sciences AB, Uppsala, Sweden). For $A \beta$ analysis, aliquots $(50 \mu \mathrm{g}$ protein) of the TBS and SDS fractions were electrophoresed on 4-12 \% Nupage Bis-Tris polyacrylamide gels (Life Technologies) and transferred to 0.45- $\mu \mathrm{m}$ PVDF membranes (Millipore). Nonspecific binding was blocked 
with $5 \%$ skim milk in TBS containing Tween 20 for $30 \mathrm{~min}$. Mouse anti-A $\beta$ antibody (clone 6E10, 1:3000), mouse anti-A $\beta$ antibody (clone $82 \mathrm{E} 1,1 \mu \mathrm{g} / \mathrm{ml}, \mathrm{IBL}$ ) and rabbit anti-ApoE antibody (A299, $5 \mu \mathrm{g} / \mathrm{ml}$, IBL) were used as the primary antibody. Horseradish peroxidaseconjugated secondary antibody (1:5000, Dako) was then applied. The blotting signals were visualized with the chemiluminescence ECL Select Western Blotting Detection Kit (GE Healthcare Bio-Sciences $\mathrm{AB}$ ) and imaged with an Image Quant LAS 4000 mini bio-molecular imager (GE Healthcare).

\section{Dot blot}

For dot blot immunoanalysis, aliquots $(50 \mu \mathrm{g}$ protein) of the TBS, SDS, and FA fractions were dotted onto $0.45-\mu \mathrm{m}$ PVDF membranes (Millipore) in a dot-blot apparatus (Bio-Rad). The blots were probed with a polyclonal antibody A11 specific for amyloid oligomers (1:1000, Biosource, Camarillo, CA) [35], followed by alkaline phosphatase-conjugated goat anti-rabbit antibody (1:5000, Thermo Scientific), and visualized with the BCIP/NBT detection system (Wako Chemicals, Osaka, Japan).

\section{ELISA}

To quantify the amount of $A \beta$ oligomers in the extracts from cat brains, we used our originally developed BAN50 single-antibody sandwich ELISA that is specific for high molecular weight $A \beta$ oligomers (10- to 20 -mers) in quadruplicate [16]. The buffers and assay procedures were similar to those described previously [34]. As a standard for inter-plate calibration, we used a 'multiple antigenic' peptide (MAP). MAP is a synthetic peptide that consists of 16 copies of epitope peptide (corresponding to $\mathrm{A} \beta 1-10)$ recognized by anti- $\mathrm{A} \beta$ monoclonal antibody (BAN50) and a single lysine core to which the epitope peptides are linked [34]. The SuperSignal ELISA Femto Maximum Sensitivity Substrate (Thermo Scientific) and a luminometer (SpectraMaxL, Molecular Devices, Osaka, Japan) were used for signal detection.

\section{Results}

\section{$A \beta$ pathology in the cat brain}

In the present study, we investigated domestic cats at various ages for AD pathologies. By immunohistochemical analysis with anti-A $\beta 42$ antibody (12 F4), we found that domestic cats older than 8 years displayed $A \beta$ deposits (Table 1). There were cases with $A \beta$ deposits that were not associated with tau immunoreactivity but there were no case with tau positive tangles in the absence of $A \beta$ deposits. On formic acid (FA)-pretreated sections, extracellular small granular $A \beta$ aggregates were observed in the neuropil throughout the cerebral cortex but rarely in the hippocampus (Fig. 1a, Additional file 1: Figure S1a). These parenchymal $\mathrm{A} \beta$ deposits in cat brains had no central core as seen in mature plaques of human $\mathrm{AD}$ and $\mathrm{Tg}$ mouse models of $\mathrm{AD}$, and were not visualized by silver staining or Congo red staining. Also, vascular $\mathrm{A} \beta$ deposition and neuritic alterations were absent. As it has been previously demonstrated [11, 26], full-length $A \beta 1-42$ aggregates in the cat brains were not stained with $A \beta N$-terminal antibody anti-A $\beta N 1$ (Fig. 1a). In addition, unlike typical SPs in human, monkey and dog brains $[7,15], A \beta$ aggregates in the cat brains were not stained with antibody against $\mathrm{N}$ terminally truncated $\mathrm{A} \beta(\mathrm{A} \beta \mathrm{pN} 3)$. ApoE protein colocalized with the small granular $A \beta$ aggregates in the cerebral cortex (Fig. 1b). In contrast to the staining pattern of $A \beta$ in the cerebral cortex, on heat-pretreated sections, intracellular accumulation of $\mathrm{A} \beta$ was detected predominantly in the pyramidal cells of the hippocampal CA1 to CA3 region but rarely in the cerebral cortex (Fig. 1c, Additional file 1: Figure S1b). ApoE immunopositivity was not detected in this area. These intracellular A $\beta$ s co-localized with Rab9 under confocal laser scanning microscopy, indicating their localization in late endosomes (Fig. 1d). The FA-vulnerable intracellular $A \beta s$ in the hippocampus always coincided with FA-resistant parenchymal A $\beta$ deposits in the cerebral cortex. The different states of $A \beta$ aggregation between the hippocampus and cerebral cortex may be due to the different neuronal cell types and/or different environments surrounding neurons in these regions. Dot blot analysis using amyloid oligomer-specific A11 antibody revealed the existence of $A \beta$ oligomers in SDS-soluble fractions, but not in FA-soluble fractions, prepared from hippocampal tissues of aged cats (Fig. 1e). Considering the vulnerability to FA treatment, these $A \beta$ oligomers were presumably derived from the intracellularly accumulated $A \beta s$ observed in immunohistochemistry. Western blotting analysis using anti-A $\beta$ antibody $6 \mathrm{E} 10$ indicated two distinct bands with molecular sizes of approximately $24 \mathrm{kDa}$ and $54 \mathrm{kDa}$, which corresponded to $\mathrm{A} \beta$ hexamers and dodecamers, respectively, in the SDS-soluble fractions (Fig. 1f). The band corresponding to $\mathrm{A} \beta$ dodecamer was detected by anti-A $\beta$ antibody 82E1, an antibody that does not react with APP (Additional file 1: Figure S2a). Neither of the bands corresponding to $A \beta$ hexamers or dodecamers was detected with anti-ApoE antibody, indicating that these oligomers are not bound with ApoE (Additional file 1: Figure S2b). The presence of $A \beta$ oligomers in the SDS-soluble fractions was also confirmed by enzyme-linked immunosorbent assay (ELISA) specific for high molecular weight $\mathrm{A} \beta$ oligomers including $\mathrm{A} \beta$ dodecamer (Additional file 1: Figure S1c).

\section{Spatial and temporal expression of tau isoforms in the cat brain}

We next examined tau pathology in cat brains. Initially, we studied the expression pattern of tau isoforms among different ages. In immunohistochemistry with RD3 and 

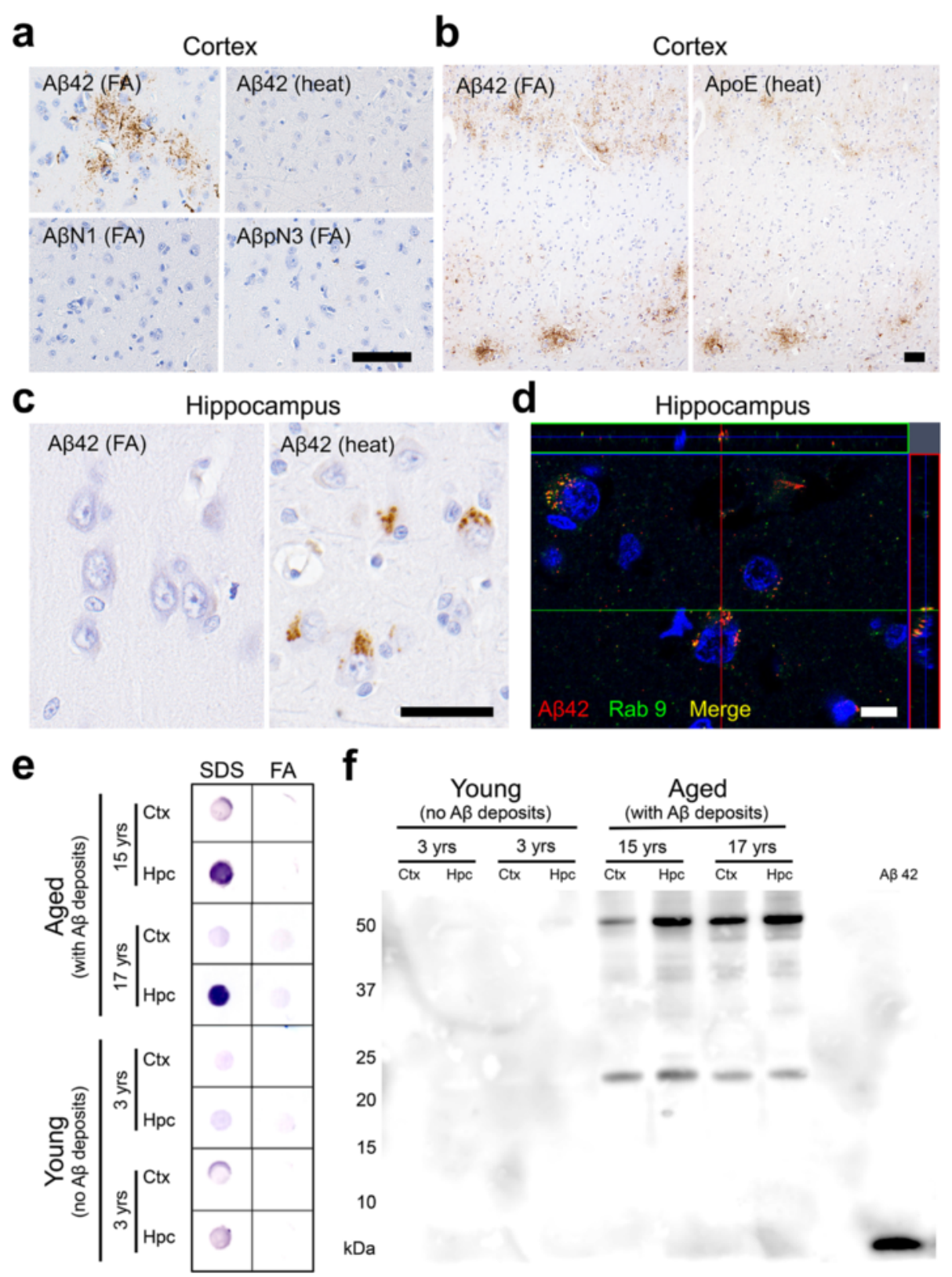

Fig. 1 A $\beta$ deposits in cat brains. a A 42 aggregates are detected in the parenchyma of the cerebral cortex with anti-A 42 antibody (12 F4) on formic acid (FA)-pretreated sections but not on heat-pretreated sections. These aggregates are not detected with antibodies against the N-terminus of human $A \beta(A \beta N 1$ and $A \beta p N 3)$. b A 342 aggregates in the cerebral cortex colocalized with ApoE. $\mathbf{c}$ Heat pretreatment revealed intracellular A 42 aggregates in the pyramidal cells of the hippocampus but not in the cortex. d Some of the intracellular Aß42 (red) aggregates colocalized with Rab9 (green). Black bars $=50 \mu \mathrm{m}$, white bar $=10 \mu \mathrm{m}$. e Dot blot analysis of SDS fractions and FA fractions of cortex (Ctx) and hippocampus (Hpc) of young cats and aged cats. A $\beta$ oligomers were detected with A11 antibody, predominantly in the SDS fraction from the hippocampus of aged cats. $\mathbf{f}$ Western blotting analysis of the SDS fraction of the Ctx and Hpc of young cats and aged cats. Two distinct bands were detected with anti-A 3 antibody $6 \mathrm{E} 10$ in the brains of aged cats: approximately $24 \mathrm{kDa}$ and 54 kDa, indicating A $\beta$ hexamers and dodecamers, respectively

RD4 antibodies specific to 3-repeat (3R) and 4-repeat (4R) tau, respectively, fetal cats were shown to express only $3 \mathrm{R}$ tau throughout the cerebrum (Fig. 2). The hippocampal pyramidal cells began to express $4 \mathrm{R}$ tau at 2 weeks postnatal age (Additional file 1: Figure S3a). In adult brains (3- to 22-year-old), both $3 \mathrm{R}$ and $4 \mathrm{R}$ tau were detected. We next investigated tau hyperphosphorylation by immunohistochemistry with AT8 (anti-pSer202/ pThr205-tau) and AT100 (anti-pThr212/pSer214-tau) antibodies. All of the cats without $A \beta$ deposits were negative for hyperphosphorylated tau, except in fetal cats AT8-positive staining was detected in the surface 


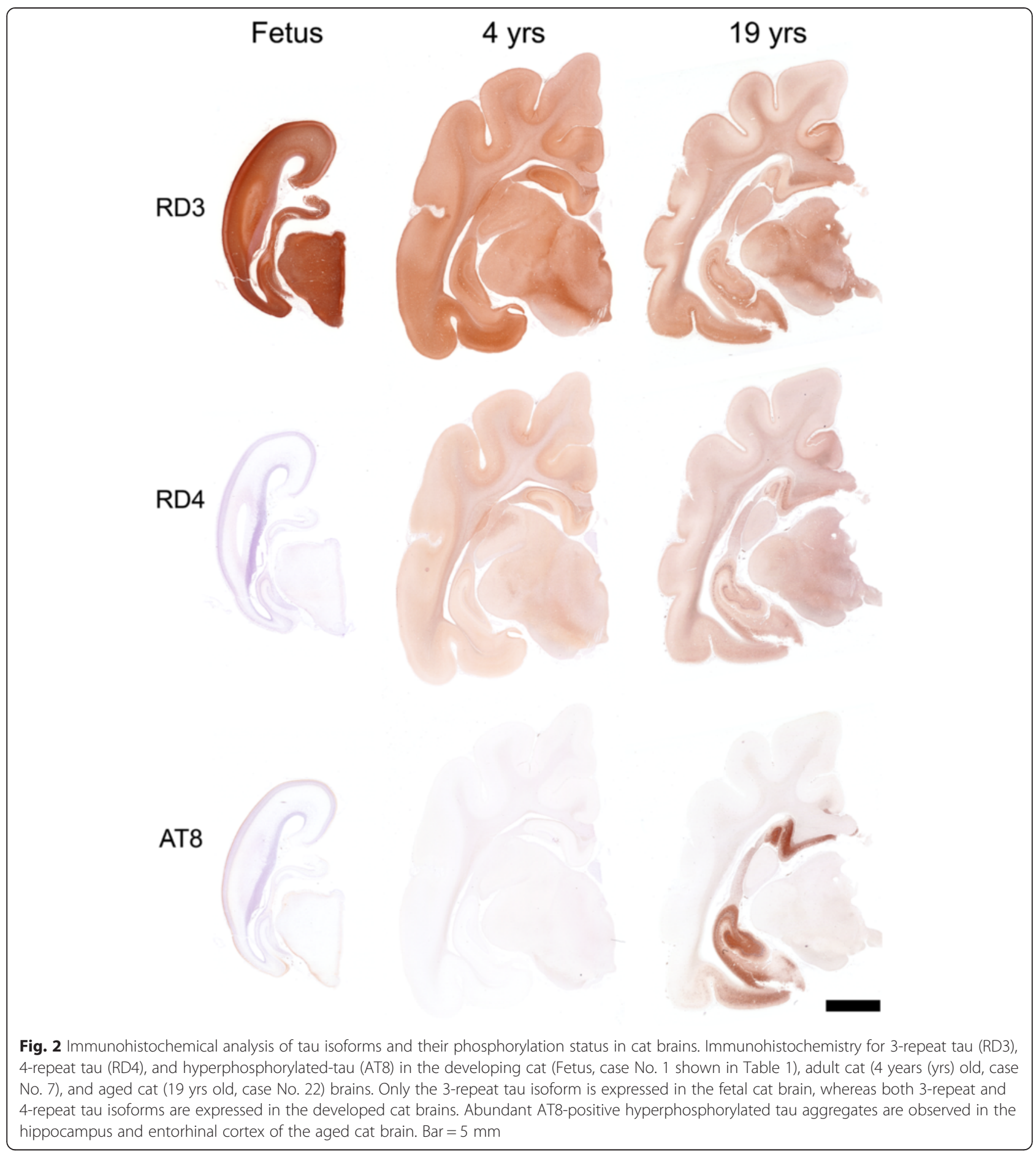

layer of the cerebrum (Table 1, Additional file 1: Figure $\mathrm{S} 3 \mathrm{~b}$ ). In some of the aged cats with $A \beta$ deposits (over 14 years old), AT8-positive staining was detected within neurons (Table 1). In mild cases, a few AT8-positive cells were observed in the entorhinal cortex (Fig. 3a), and in more severe cases, numerous AT8-positive cells were detected throughout the entorhinal cortex, hippocampus and also mildly in the cerebral cortex (Figs. 2, 3b, Table 1). Also, a few AT8-positive cells were observed in the locus ceruleus of aged cats (Fig. 3b). We noticed that the cerebrums were atrophied in aged cats compared to those in young cats (Fig. 2). The agedependent change in tau isoform expression was confirmed with western blotting with anti-tau (TAU-5), RD3, and RD4 antibodies of TBS-soluble fractions prepared from the cerebrums (Fig. 4a). Western blotting analysis 


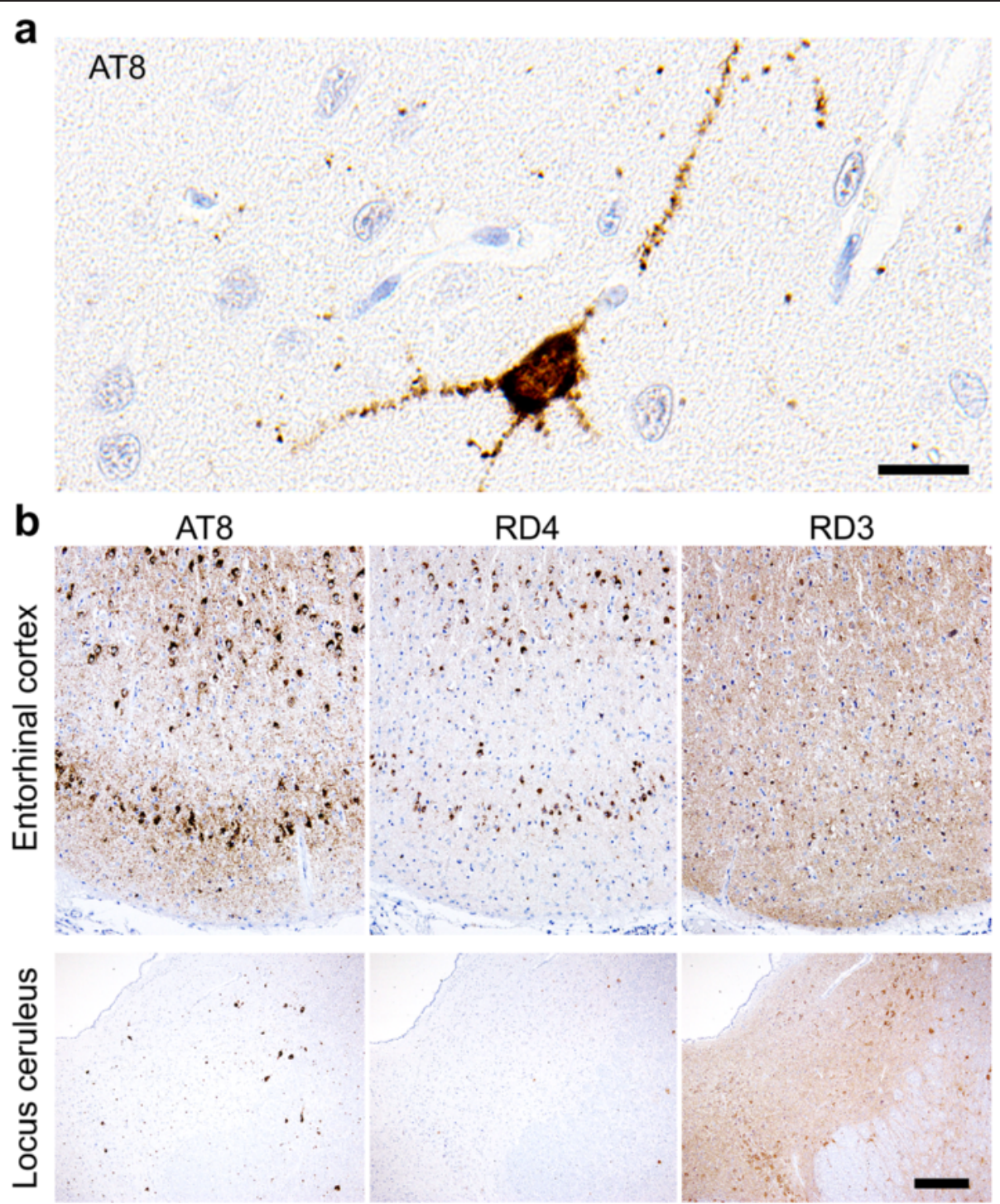

Fig. 3 Hyperphosphorylated tau accumulation in the entorhinal cortex and locus ceruleus of cat brains. a Immunohistochemistry of the entorhinal cortex of a cat with mild hyperphosphorylated tau accumulation (15-year-old, case No. 13) for hyperphosphorylated-tau (AT8). The neuronal soma and dendrites are positively stained for hyperphosphorylated tau. Bar $=20 \mu \mathrm{m}$. b Immunohistochemistry of the entorhinal cortex and locus ceruleus of a cat with severe hyperphosphorylated tau accumulation (14-year-old, case No. 12) for AT8, 3-repeat tau (RD3), and 4-repeat tau (RD4). AT8-positive aggregates are also positively stained for 3-repeat tau and 4-repeat tau on consecutive sections. Bar $=300 \mu \mathrm{m}$

with AT8 and AT100 antibodies indicated that sarkosylinsoluble, guanidine $\mathrm{HCl}$-soluble fractions prepared from hippocampal tissues of aged cats contained abundant hyperphosphorylated tau (Fig. 4b). These insoluble tau species, which showed a smear profile in western blots, were shown to consist of both $3 \mathrm{R}$ and $4 \mathrm{R}$ tau isoforms, which was proven after dephosphorylation of the samples (Fig. 4b).

\section{NFT in aged cat brains}

The presence of hyperphosphorylated tau in insoluble brain fractions implies that these tau proteins may form NFTs. Thus, we examined NFT formation in aged cats by
Gallyas-Braak silver staining and confirmed silver positive fibrillar aggregates in the neuronal somata and in neurites (Fig. 5a). By electron microscopy, bundles of filaments were observed in the neuronal somata and neurites (Fig. 5b). These filaments had widths of $15-25 \mathrm{~nm}$ and showed either straight pattern or paired twisted pattern. In the twisted area, lengths between the constrictions were 80-100 $\mathrm{nm}$. These ultrastructural findings were comparable to those of NFTs in AD [2], although the lengths between the constrictions of the paired twisted filaments tend to be a little longer than in AD. Abundant NFTs were found in the hippocampus (Fig. 5c), but rarely in the cerebral cortex (Fig. 2), of aged cats. Notably, this distribution 

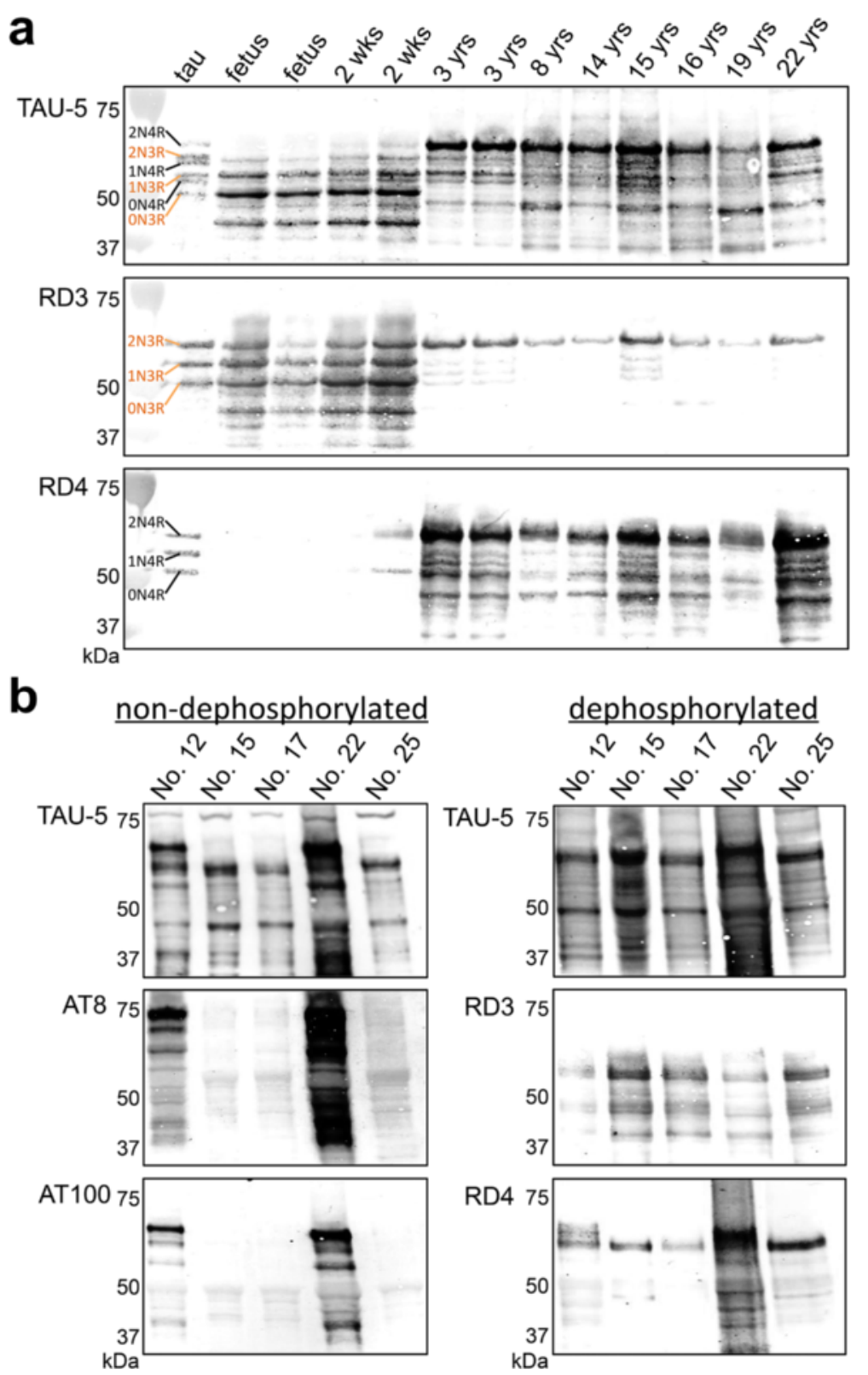

Fig. 4 Western blotting analysis of tau isoforms and their phosphorylation status in cat brains. a Western blotting of TBS-soluble fractions obtained from the hippocampus of various ages and treated with alkaline phosphatase (AP). The left lane (tau) shows the six isoforms of human tau (recombinantly produced): three 3-repeat tau isoforms (2N3R, 1N3R, 0N3R) and three 4-repeat tau isoforms (2N4R, 1N4R, 0N4R). In the fetal brain, only the 3-repeat tau isoforms are expressed. In the adult cat brains, all six isoforms are detected using anti-tau antibody (TAU-5) and also 3-repeat tau (RD3), and 4-repeat tau (RD4) antibodies. b Western blotting of sarkosyl-insoluble guanidine HCl-soluble fractions obtained from the hippocampus of aged cat brains without AP treatment (left) and with AP treatment (right). In cat hippocampi that were immunohistochemically positive for hyperphosphorylated tau (cases No. 12 and 22), AT8- and AT100-positive tau proteins are detected. In these cats, the smear-like band pattern resolved into clear lower molecular weight bands consisting of both 3-repeat and 4-repeat tau isoforms after dephosphorylation treatment

of NFTs in aged cat brains corresponded to that of intracellular $\mathrm{A} \beta$ oligomers. In consecutive sections, NFTs were colocalized with hyperphosphorylated tau (AT8 and AT100) and ubiquitin (Fig. 5c). Regarding the affected cell types, hyperphosphorylated tau was detected mainly in neurons (MAP2-positive) and in some oligodendrocytes (Olig2- positive), but not in astrocytes (GFAP-positive) (Fig. 5d). Aggregates in the oligodendrocytes were also detected by Gallyas-Braak staining (Fig. 5a). The absence of astrocytic tau inclusion bodies, such as astrocytic plaques or tuftshaped astrocytes, indicates that the hyperphosphorylated tau aggregates found in feline brains differ from those 


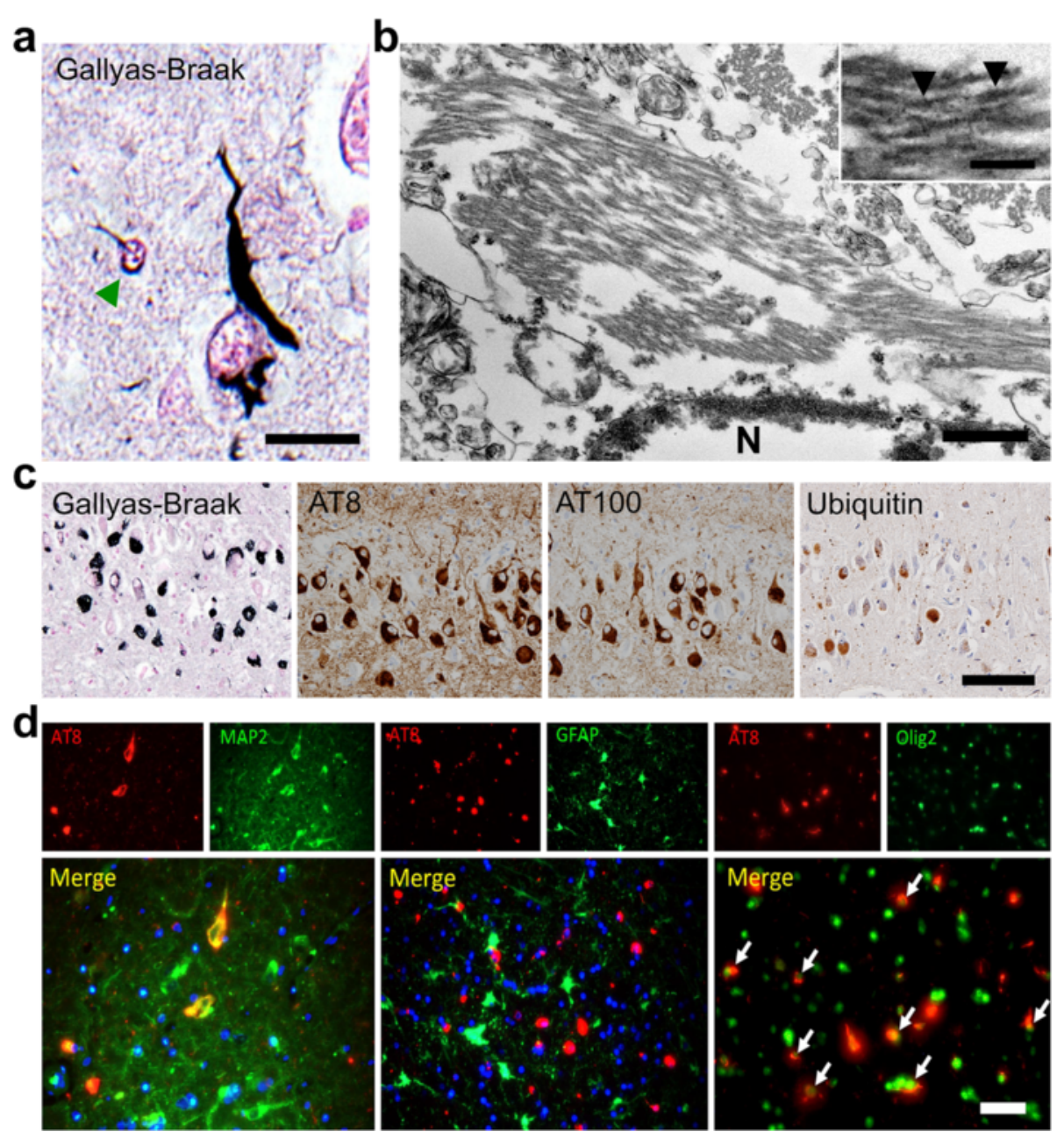

Fig. 5 NFTs in aged cats brains. a Gallyas-Braak staining-positive argyrophilic aggregates are observed mainly in the neuronal soma, neurites, and also in some oligodendroglial cells (green arrowhead) in the entorhinal cortex of aged cat brain. Bar $=20 \mu \mathrm{m}$. $\mathbf{b}$ Transmission electron microscopy of NFT in the hippocampus. Bundles of filaments are observed in the neuronal soma either in strait form or paired twisted form. For the paired twisted form, the lengths between the constrictions (arrowheads) were $80-100 \mathrm{~nm}$. Bars $=500 \mathrm{~nm}$ and $100 \mathrm{~nm}$ (inset). N: nucleus. c Consecutive sections of hippocampus show AT8-, AT100-, and ubiquitin-immunopositivity for NFTs. Bar $=100 \mu \mathrm{m}$. d AT8-positive (red) hyperphosphorylated tau is observed in MAP2-positive (green) neurons (left) and Olig2-positive (green) oligodendrocytes (right, white arrows), but not in GFAP-positive (green) astrocytes (middle). Bar $=50 \mu \mathrm{m}$

associated with corticobasal degeneration and progressive supranuclear palsy [28].

\section{Hippocampal neuronal loss in cats with NFT}

Although neuronal loss in the entorhinal cortex and hippocampus is considered to be an early event in $\mathrm{AD}$ $[22,59]$, it has not been detected in combination with $\mathrm{A} \beta$ and tau pathologies in non-human species $[50,58]$. Because hippocampal neurodegeneration is important in the manifestation of AD [30], we assessed neuronal loss in the hippocampus of the cats. The number of NeuNpositive cells in the hippocampal CA1 region were compared among three groups: young cats with neither $A \beta$ deposits nor NFTs (A $\beta$-/NFT-, $n=3$, mean age 3.7 years old), aged cats with only cerebral $A \beta$ deposits but no hippocampal NFTs (A $\beta+/ \mathrm{NFT}-, n=3$, mean age 18.0 years old), and aged cats with both cerebral $A \beta$ deposits and hippocampal NFTs $(\mathrm{A} \beta+/ \mathrm{NFT}+, n=3$, mean age 17.6 years old). In the $A \beta+/ N F T$ - group, NeuN-positive cells were slightly but not significantly decreased compared to those in the A $\beta$-/NFT- group $(P=0.076$, Fig. 6a, b), whereas the $\mathrm{A} \beta+/ \mathrm{NFT}+$ group showed a significant decrease in NeuN-positive cells compared to the other two groups $(P<0.001$, Fig. 6a, b). Ghost tangles were visible on HE-stained sections suggesting the death of tangle bearing neurons (Fig. 6c, black arrows). These dead neurons were negative for $\mathrm{NeuN}$ and the live cells were positive for NeuN. Also, inclusions composed of hyperphosphorylated tau (AT8- and AT100positive on consecutive sections) were occasionally 


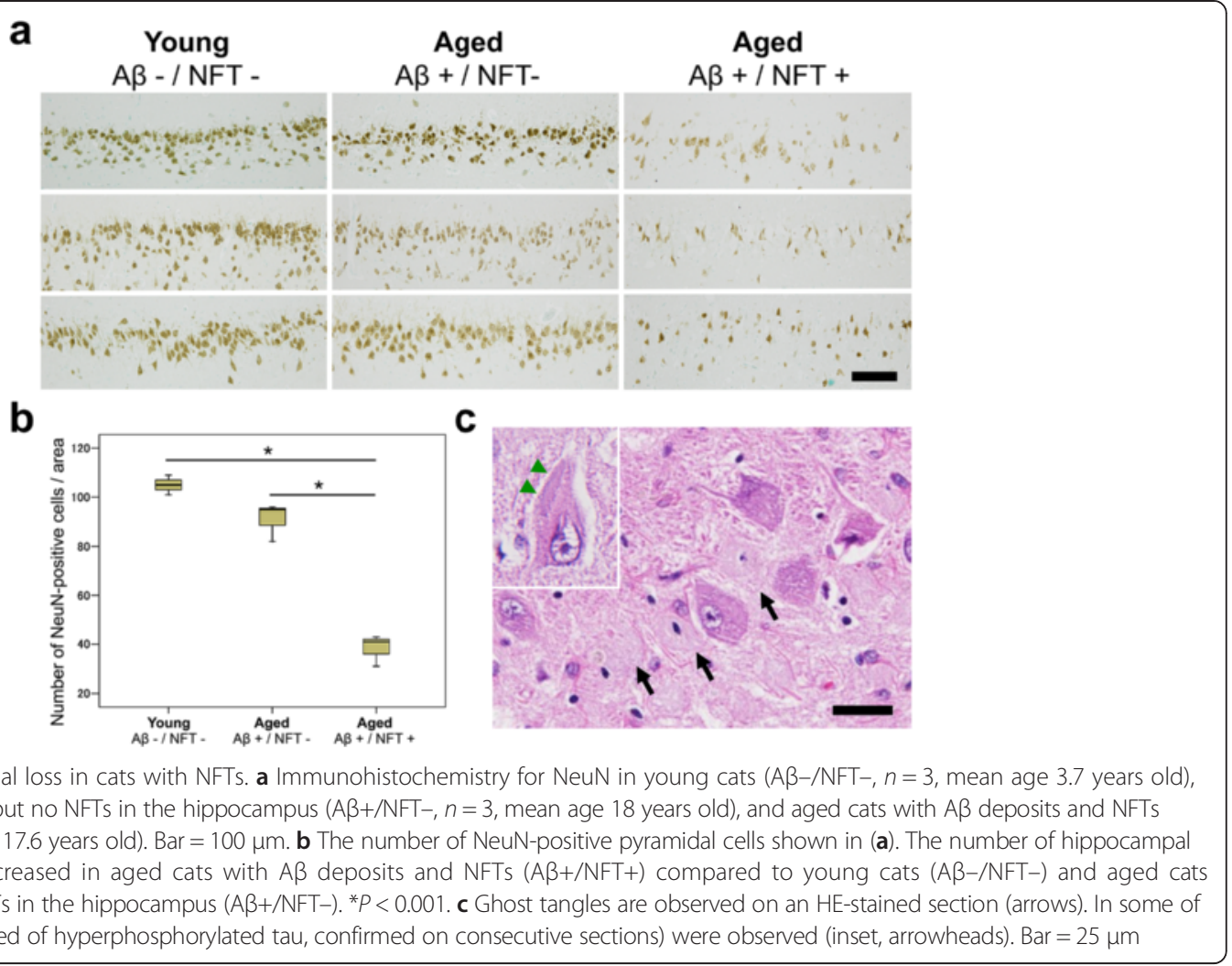

observed on HE-stained sections (Fig. 6c, inset, green arrowheads).

\section{Discussion}

In this study, we found that aged domestic cats develop not only $\mathrm{A} \beta$ deposits but also NFTs and neuronal loss in their brains. Though it has been shown that NFT occurs earlier than senile plaque in humans, in cats $A \beta$ deposits (diffuse plaques in the cerebral cortex and intracellular $A \beta$ oligomers in the hippocampus) started to occur at 8 years of age, and NFTs and neuronal loss at 14 years of age. The distribution, affected cells, tau isoforms and ultrastructure of the NFTs were comparable to those of AD. NFT formation and subsequent neuronal loss occurred in the same brain region as that of intracellular $A \beta$ oligomer accumulation, i.e., the hippocampus. These findings have also been seen in Tg mouse models and human $\mathrm{AD}$ patients $[1,17,41,57]$. The early occurrence of these pathologies makes this animal species an attractive model for studying therapeutic intervention for AD.

What factors enable domestic cats to develop full $\mathrm{AD}$ pathologies, particularly NFTs and neuronal loss, in its shorter life-span than humans? Current evidence suggests that $A \beta$ and tau interact to accelerate each other's pathology and that tau hyperphosphorylation and subsequent NFT formation are induced by pathological $A \beta$ species, i.e., $A \beta$ oligomers $[3,29]$. Our results demonstrating that
NFTs formed in the same brain region as intracellular $A \beta$ oligomers in aged cats may imply the involvement of $A \beta$ oligomers in the initiation (early stage) of NFT development. Furthermore, these $A \beta$ oligomers consisted of $A \beta$ hexamers and dodecamers (Fig. 1c), which are considered to be pathological $A \beta$ species and to be associated with pathological tau conformers in $\mathrm{AD}[3,4,37]$. The accumulation of $A \beta$ oligomers in domestic cats presumably comes from its $A \beta$ sequence, in which the 7 th amino acid residue is different from that of human $A \beta[5,39]$ (Additional file 1: Table S1). There are two known familial AD-linked mutations in the $\mathrm{N}$-terminal region of $A \beta$ : the English mutation (H6R) and the Tottori mutation (D7N), both of which result in increased formation of $A \beta$ oligomers $[9,43]$. Also, racemization of the 7th Asp residue affects the $A \beta$ aggregation property and inhibits its fibril formation [53]. Thus, the substitution of the 7th amino acid of human $A \beta$ likely results in enhanced oligomerization and reduced fibrilization of $A \beta$, which may explain why cat $A \beta$ abundantly accumulates into oligomeric forms.

This study demonstrated that domestic cats develop non-argyrophilic small granular $A \beta$ aggregates in the cerebral cortex and FA-vulnerable intracellular $A \beta$ oligomers in the hippocampus, but not argyrophilic SPs. ApoE colocalized with the non-argyrophilic $A \beta$ aggregates in the cerebral cortex that lack immunoreactivity 
against anti- $\mathrm{A} \beta \mathrm{N}$-terminus antibodies. The same finding has been described with newly formed $A \beta$ deposits in the human brain indicating that the $\mathrm{N}$-terminal epitope of the $\mathrm{A} \beta$ is bound with ApoE [51]. We consider that the lack of SP formation is important for the early development of NFTs in cat brains. Many animal species including monkeys, dogs, bears, camels, and horses, whose $A \beta$ sequence is identical to that of human $A \beta$ (Additional file 1: Table S1), spontaneously develop abundant argyrophilic SPs similar to human SPs in old age, but do not develop NFTs $[6,15,33,40,48,56,58]$. It is known that the extent of intraneuronal $\mathrm{A} \beta 42$ labeling is inversely correlated with the progression of SP in double $\mathrm{Tg}\left(\mathrm{APP}_{\mathrm{SWE} / \mathrm{London}}\right.$ and mutant PS1 $\left.1_{\mathrm{M} 146 \mathrm{~L}}\right)$ and triple $\mathrm{Tg}\left(\mathrm{APP}_{\mathrm{SWE}}\right.$, tau $\mathrm{P}_{\mathrm{P} 01 \mathrm{~L}}$, and $\mathrm{PS}_{\mathrm{M} 146 \mathrm{~V}}$ knock-in) mice, suggesting that the amount of intraneuronal soluble $A \beta$ is in equilibrium with the amount of extraneuronal insoluble fibrillar $A \beta[36,42]$. Furthermore, the number of $A \beta$ oligomers present within the brain is inversely correlated with the severity of SP in aged dogs [25]. Thus it has been proposed that SPs are formed to sequester toxic $A \beta$ oligomers, preventing $A \beta$ oligomer-induced pathologies including NFT formation [3]. In animal species that express human-type $A \beta$, SPs may be gathering toxic $A \beta$ oligomers as "trash bins", preventing $A \beta$ oligomers from interacting with tau and proceeding to NFT formation [12, 38, 52] (Table 2). Uniquely among animals, humans have extended their life-span to overwhelm the buffering capacity of SPs, and A $\beta$ oligomers that have overflowed SPs could cause tau pathologies. In cats, on the other hand, the buffering stage (SP formation) is skipped, and therefore, tau pathologies would appear soon after $A \beta$ oligomer formation in a shorter lifespan. A very similar type of $A \beta$ to cat $A \beta$ is known in human familial AD. Patients and $\mathrm{Tg}$ mice with the APP Osaka (E693 $\Delta$ ) mutation, which corresponds to E22 $\Delta$ in the $A \beta$ sequence, accumulate abundant $A \beta$ oligomers within neurons without developing SPs and showed early cognitive dysfunction [54, 55]. Furthermore, when the $\mathrm{Tg}$ mice were crossbred with tau- $\mathrm{Tg}$ mice expressing both $3 \mathrm{R}$ and $4 \mathrm{R}$ human tau, the resultant double $\mathrm{Tg}$ mice develop NFTs [57].

Besides the accumulation of $A \beta$ oligomers, other factors may also be involved in NFT formation in domestic cats.
We first assumed that the expression pattern of tau isoforms might influence NFT formation. The expression patterns of $3 R$ and $4 R$ tau differ among animal species and developmental stages [10, 20,31]. In humans and mice, only $3 \mathrm{R}$ tau isoforms are expressed in the fetal brain. In adults, whilst both $3 \mathrm{R}$ and $4 \mathrm{R}$ tau isoforms are expressed in humans, only $4 \mathrm{R}$ tau isoforms are expressed in mice. As mentioned above, mice do not develop NFT, but tau $\mathrm{Tg}$ mouse strains that express both $3 \mathrm{R}$ and $4 \mathrm{R}$ tau isoforms do [57]. In the present study, we showed that only $3 \mathrm{R}$ tau isoforms are expressed in the brains of fetal cats, whereas both $3 R$ and $4 R$ tau isoforms were detected in the brains of adult cats. Thus, the expression of both $3 R$ and $4 R$ tau isoforms seems to be a prerequisite for NFT formation. However, chimpanzees, which also express both $3 \mathrm{R}$ and $4 \mathrm{R}$ tau isoforms in adult ages, do not develop NFTs except in the case of brain infarction $[19,23,27,44,48]$. We also considered the involvement of the tau amino acid sequence. Mouse tau shows only $83 \%$ homology with human tau, whereas cat tau shows $93 \%$ homology with human tau (Table 2, Additional file 1: Table S2). However, again, chimpanzees whose tau sequence is identical to that of human tau do not develop NFTs. These observations suggest that tau isoform expression and the amino acid sequence may be important for NFT formation, but the pathology does not simply depend on either of these factors.

The present study detected intracellular $A \beta$ accumulation, NFT formation, and neuronal loss in the hippocampi of aged cats' brains. However, no significant neuronal loss was observed in the brains of cats that were free from NFT, even when intracellular $A \beta$ was present (Fig. 6a, b). This implies that NFTs are important for hippocampal neurodegeneration, as has been indicated in studies of human AD [30]. Some studies have suggested that the toxic tau species is oligomers, and NFTs are formed to sequester those oligomers [45]. If so, when NFTs are saturated, tau oligomers would overflow causing neurodegeneration. This may explain our observation that neuronal loss and NFTs were observed in the same brain region.

In a previous report, AT8-positivity was detected in cats with seizures [26]. In the present study, none of the cats

Table 2 Comparison of AD pathology in different species [5, 19, 25, 27, 31, 33, 39, 44, 48]

\begin{tabular}{|c|c|c|c|c|c|c|c|c|}
\hline \multirow[t]{2}{*}{ Species } & \multirow[t]{2}{*}{ Life span } & \multicolumn{3}{|l|}{$A \beta$} & \multicolumn{3}{|l|}{ Tau } & \multirow[t]{2}{*}{ Neuron los } \\
\hline & & Sequence vs. human & Oligomers & $\overline{S P}$ & Sequence vs. human & Isoforms ${ }^{a}$ & $\overline{\mathrm{NFT}}$ & \\
\hline Human & 80 yrs & - & Yes & Yes & - & $3 R+4 R(6)$ & Yes & Yes \\
\hline Chimpanzee & $60 \mathrm{yrs}$ & $100 \%$ & ND & Yes & $100 \%$ & $3 R+4 R(6)$ & No & No \\
\hline Dog & $20 \mathrm{yrs}$ & $100 \%$ & Yes & Yes & $92 \%$ & $3 R+4 R(4)$ & No & No \\
\hline Cat & $20 \mathrm{yrs}$ & 1 a.a. different & Yes & No & $93 \%$ & $3 R+4 R(6)$ & Yes & Yes \\
\hline Mouse & $2 \mathrm{yrs}$ & 3 a.a. different & No & No & $89 \%$ & $4 \mathrm{R}(3)$ & No & No \\
\hline
\end{tabular}

aparenthesis indicate the number of total tau isoforms; yrs, years; a.a., amino acid(s); ND, no data 
had been reported to have seizures. Also, we performed full necropsy of all the cases and did not find lesions that would cause seizures, thus AT8-positivity and the severe neuronal loss are not related to seizure activity in cats.

\section{Conclusions}

It has been argued that the pathology observed in $\mathrm{Tg}$ mice harboring mutations in their APP, PSEN, and/or $M A P T$ is different from that seen in human AD, probably due to the abnormally high expression levels and/or altered aggregation properties of $\mathrm{A} \beta$ and tau $[13,14,41$, 46]. Non- $\mathrm{Tg}$ animals, such as monkeys and dogs, develop SP composed of human-type $A \beta$ as they age, but these animals do not experience NFT-induced neurodegeneration. Here, we demonstrated that domestic cats spontaneously develop $A \beta$ deposition, NFT formation, and neuronal loss, during their shorter life-span (about 20 years) than that of humans. Based on these pathological features of aged cat brains, we propose that domestic cats could be a valuable natural animal model of human $\mathrm{AD}$, as aged cats display $\mathrm{A} \beta$ and tau pathologies earlier than humans, and thus, would be useful for investigating the pathogenesis of and possible treatments for the disease.

\section{Additional file}

\section{Additional file 1: Figure S1. A $\beta$ deposition in cat brains. (a)}

Immunohistochemistry of the cerebrum of a 17-year-old cat (case No. 20) for $A \beta 42$ with FA pretreatment. $A \beta 42$ aggregates are observed in the cerebral cortex but not in the hippocampus by immunohistochemistry with FA pretreatment. Higher magnification of the parietal lobe (right). Bar $=100 \mu \mathrm{m}$. (b) Negative control (without primary antibody) of Fig. 1c. No staining is detected in the cytoplasm. (c) ELISA for high molecular weight $A \beta$ oligomers. Higher amounts of $A \beta$ oligomers were seen in the brains of aged cats (15-year-old, case No. 15; 17-year-old, case No. 20) compared to the brains of young cats (3-year-old, case No. 5; 3-year-old, case No. 6). The ratio of MAP level per unit of $A \beta$ concentration varies depending on the sizes of the A oligomers. One pM of the MAP can be estimated to yield the same signal as $1.56 \mathrm{pM}$ (for 20-mer) to 5.0 pM (for 100-mer) of A 342 oligomers [33]. Ctx, cortex; Hpc, hippocampus. Figure S2 Western blotting analysis of the SDS fraction of the cortex (Ctx) and hippocampus (Hpc) of young cats and aged cats. (a) The band corresponding to $A \beta$ dodecamer is detected by anti-A $\beta$ antibody $82 \mathrm{E} 1$. (b) $A \beta$ oligomers that are demonstrated in Fig. If are not detected by anti-ApoE antibody A299. Figure S3 Expression of tau isoforms in the developing cat brain. (a) Immunohistochemistry of the hippocampus CA1 region of a fetus (case No. 1), a 2-week-old cat (case No. 3), and a 4-year-old cat (case No. 7) for 3-repeat tau (RD3), 4-repeat tau (RD4), and hyperphosphorylated tau (AT8). Only the 3-repeat tau isoform is expressed in the fetal hippocampus. The hippocampal pyramidal cells begin to express 4-repeat tau in the 2-week-old cat (arrows). Both 3-repeat and 4-repeat tau isoforms are expressed in the hippocampus of adult cat brain. $\mathrm{Bar}=50 \mu \mathrm{m}$. (b) Immunohistochemistry of the cerebral cortex of a fetal cat for hyperphosphorylated tau (AT8 and AT100). The surface layer of the fetal cerebral cortex is positive for AT8 and negative for AT100. Bar $=100 \mu \mathrm{m}$. Table S1 A $\beta$ protein amino acid sequences of different animal species. Table S2 Tau protein amino acid sequences of different animal species. (PDF $10834 \mathrm{~kb}$ )

\section{Competing interests}

The authors declare no conflict of interest.

\section{Authors' contributions}

JKC, TTokuda and KU designed the study. JKC, TTokuda, KU, RI and HT performed the research. ET, YU and TTomiyama supported experimenta design and data analysis. JKC, TTokuda, KU, TTomiyama and HN wrote the manuscript. All authors read and approved the final manuscript.

\section{Acknowledgments}

This research was funded by Grants-in-Aid for Scientific Research, Japan Society for the Promotion of Science, research project number 24780283. The authors would like to thank Dr. Fumiko Ishizuna for her excellent technical assist with electron microscopy.

\section{Author details}

${ }^{1}$ Department of Veterinary Pathology, Graduate School of Agricultural and Life Sciences, The University of Tokyo, Tokyo, Japan. ${ }^{2}$ Department of Molecular Pathobiology of Brain Diseases, Kyoto Prefectural University of Medicine, Kyoto, Japan. ${ }^{3}$ Department of Neurology, Kyoto Prefectural University of Medicine, Kyoto, Japan. ${ }^{4}$ Laboratory of Veterinary Pathology, School of Veterinary Medicine, Azabu University, Kanagawa, Japan. ${ }^{5}$ Department of Neuroscience, Osaka City University Graduate School of Medicine, Osaka, Japan.

Received: 19 November 2015 Accepted: 19 November 2015 Published online: 10 December 2015

\section{References}

1. Aho L, Pikkarainen M, Hiltunen M, Leinonen V, Alafuzoff I. Immunohistochemical visualization of amyloid-beta protein precursor and amyloid-beta in extra- and intracellular compartments in the human brain J Alzheimers Dis. 2010;20:1015-28. doi:10.3233/JAD-2010-091681.

2. Arima K. Ultrastructural characteristics of tau filaments in tauopathies: immuno-electron microscopic demonstration of tau filaments in tauopathies. Neuropathology. 2006;26:475-83.

3. Benilova I, Karran E, De Strooper B. The toxic A $\beta$ oligomer and Alzheimer's disease: an emperor in need of clothes. Nat Neurosci. 2012;15:349-57. doi:10.1038/nn.3028.

4. Bernstein SL, Dupuis NF, Lazo ND, Wyttenbach T, Condron MM, Bitan G, et al. Amyloid- $\beta$ protein oligomerization and the importance of tetramers and dodecamers in the aetiology of Alzheimer's disease. Nat Chem. 2009;1:326-31. doi:10.1038/nchem.247.

5. Brinkmalm G, Portelius E, Öhrfelt A, Mattsson N, Persson R, Gustavsson MK, et al. An online nano-LC-ESI-FTICR-MS method for comprehensive characterization of endogenous fragments from amyloid $\beta$ and amyloid precursor protein in human and cat cerebrospinal fluid. J Mass Spectrom. 2012;47:591-603. doi:10.1002/jms.2987.

6. Capucchio MT, Márquez M, Pregel P, Foradada L, Bravo M, Mattutino $\mathrm{G}$, et al. Parenchymal and vascular lesions in ageing equine brains: histological and immunohistochemical studies. J Comp Pathol. 2010; 142:61-73. doi:10.1016/j.jcpa.2009.07.007.

7. Chambers JK, Mutsuga M, Uchida K, Nakayama H. Characterization of A $\mathrm{BpN} 3$ deposition in the brains of dogs of various ages and other animal species. Amyloid. 2011;18:63-71. doi:10.3109/13506129.2011.570385.

8. Chambers JK, Uchida K, Harada T, Tsuboi M, Sato M, Kubo M, et al. Neurofibrillary tangles and the deposition of a beta amyloid peptide with a novel N-terminal epitope in the brains of wild Tsushima leopard cats. PLoS One. 2012;7, e46452. doi:10.1371/journal.pone.0046452.

9. Chen WT, Hong CJ, Lin YT, Chang WH, Huang HT, Liao JY, et al. Amyloid-beta $(A \beta) D 7 H$ mutation increases oligomeric $A \beta 42$ and alters properties of $A \beta$-zinc/copper assemblies. PLoS One. 2012;7, e35807. doi:10.1371/journal.pone.0035807.

10. Couchie D, Nunez J. mmunological characterization of microtubule-associated proteins specific for the immature brain. FEBS Lett. 1985;188:331-5.

11. Cummings BJ, Satou T, Head E, Milgram NW, Cole GM, Savage MJ, et al. Diffuse plaques contain C-terminal A beta 42 and not A beta 40: evidence from cats and dogs. Neurobiol Aging. 1996:17:653-9.

12. De Felice FG, Wu D, Lambert MP, Fernandez SJ, Velasco PT, Lacor PN, et al. Alzheimer's disease-type neuronal tau hyperphosphorylation induced by A beta oligomers. Neurobiol Aging. 2008;29:1334-47.

13. Duyckaerts C, Potier MC, Delatour B. Alzheimer disease models and human neuropathology: similarities and differences. Acta Neuropathol. 2008;115:5-38. 
14. Frank S, Clavaguera F, Tolnay M. Tauopathy models and human neuropathology: similarities and differences. Acta Neuropathol. 2008;115:39-53.

15. Frost JL, Le KX, Cynis H, Ekpo E, Kleinschmidt M, Palmour RM, et al. Pyroglutamate- 3 amyloid- $\beta$ deposition in the brains of humans, non-human primates, canines, and Alzheimer disease-like transgenic mouse models. Am J Pathol. 2013;183:369-81. doi:10.1016/j.ajpath.2013.05.005.

16. Fukumoto $H$, Tokuda $T$, Kasai $T$, Ishigami N, Hidaka H, Kondo M, et al. High-molecular-weight beta-amyloid oligomers are elevated in cerebrospinal fluid of Alzheimer patients. FASEB J. 2010;24:2716-26. doi:10.1096/fj.09-150359.

17. Gouras GK, Tampellini D, Takahashi RH, Capetillo-Zarate E. Intraneuronal beta-amyloid accumulation and synapse pathology in Alzheimer's disease. Acta Neuropathol. 2010;119:523-41. doi:10.1007/s00401-010-0679-9.

18. Gunn-Moore DA, McVee J, Bradshaw JM, Pearson GR, Head E, Gunn-Moore FJ. Ageing changes in cat brains demonstrated by beta-amyloid and AT8immunoreactive phosphorylated tau deposits. J Feline Med Surg. 2006;8:234-42.

19. Gearing M, Rebeck GW, Hyman BT, Tigges J, Mirra SS. Neuropathology and apolipoprotein E profile of aged chimpanzees: implications for Alzheimer disease. Proc Natl Acad Sci U S A. 1994;91:9382-6.

20. Goedert $M$, Jakes R. Expression of separate isoforms of human tau protein: correlation with the tau pattern in brain and effects on tubulin polymerization. EMBO J. 1990:9:4225-30.

21. Goedert M, Spillantini MG, Cairns NJ, Crowther RA. Tau proteins of Alzheimer paired helical filaments: abnormal phosphorylation of all six brain isoforms. Neuron. 1992;8:159-68.

22. Gómez-Isla T, Price JL, McKeel Jr DW, Morris JC, Growdon JH, Hyman BT. Profound loss of layer II entorhinal cortex neurons occurs in very mild Alzheimer's disease. J Neurosci. 1996;16:4491-500.

23. Götz J, Ittner LM. Animal models of Alzheimer's disease and frontotemporal dementia. Nat Rev Neurosci. 2008;9:532-44. doi:10.1038/nrn2420.

24. Hardy JA, Higgins GA. Alzheimer's disease: the amyloid cascade hypothesis. Science. 1992;256:184-5.

25. Head E. A canine model of human aging and Alzheimer's disease. Biochim Biophys Acta. 1832;2013:1384-9. doi:10.1016/j.bbadis.2013.03.016.

26. Head E, Moffat K, Das P, Sarsoza F, Poon WW, Landsberg G, et al. Betaamyloid deposition and tau phosphorylation in clinically characterized aged cats. Neurobiol Aging. 2005:26:749-63.

27. Holzer M, Craxton M, Jakes R, Arendt T, Goedert M. Tau gene (MAPT) sequence variation among primates. Gene. 2004;341:313-22.

28. Ikeda K, Akiyama H, Arai T, Nishimura T. Glial tau pathology in neurodegenerative diseases: their nature and comparison with neuronal tangles. Neurobiol Aging. 1998;19:S85-91.

29. Ittner LM, Götz J. Amyloid- $\beta$ and tau-a toxic pas de deux in Alzheimer's disease. Nat Rev Neurosci. 2011;12:65-72. doi:10.1038/nrn2967.

30. Jack Jr CR, Knopman DS, Jagust WJ, Petersen RC, Weiner MW, Aisen PS, et al. Tracking pathophysiological processes in Alzheimer's disease: an updated hypothetical model of dynamic biomarkers. Lancet Neurol. 2013; 12:207-16. doi:10.1016/S1474-4422(12)70291-0

31. Janke C, Beck M, Stahl T, Holzer M, Brauer K, Bigl V, et al. Phylogenetic diversity of the expression of the microtubule-associated protein tau: implications for neurodegenerative disorders. Brain Res Mol Brain Res. 1999;68:119-28.

32. Johnson WE, Eizirik E, Pecon-Slattery J, Murphy WJ, Antunes A, Teeling E, et al. The late Miocene radiation of modern Felidae: a genetic assessment. Science. 2006;311:73-7.

33. Johnstone EM, Chaney MO, Norris FH, Pascual R, Little SP. Conservation of the sequence of the Alzheimer's disease amyloid peptide in dog, polar bear and five other mammals by cross-species polymerase chain reaction analysis. Brain Res Mol Brain Res. 1991:10:299-305.

34. Kasai T, Tokuda T, Taylor M, Nakagawa M, Allsop D. Utilization of a multiple antigenic peptide as a calibration standard in the BAN50 single antibody sandwich ELISA for A $\beta$ oligomers. Biochem Biophys Res Commun. 2012;422: 375-80. doi:10.1016/j.bbrc.2012.04.146.

35. Kayed R, Canto I, Breydo L, Rasool S, Lukacsovich T, Wu J, et al. Conformation dependent monoclonal antibodies distinguish different replicating strains or conformers of prefibrillar $A \beta$ oligomers. Mol Neurodegener. 2010;5:57. doi:10.1186/1750-1326-5-57.

36. Langui $D$, Girardot N, El Hachimi KH, Allinquant B, Blanchard V, Pradier L, et al. Subcellular topography of neuronal Abeta peptide in APPXPS1 transgenic mice. Am J Pathol. 2004;165:1465-77.
37. Lesné SE, Sherman MA, Grant M, Kuskowski M, Schneider JA, Bennett DA et al. Brain amyloid- $\beta$ oligomers in ageing and Alzheimer's disease. Brain. 2013;136:1383-98. doi:10.1093/brain/awt062.

38. Ma QL, Yang F, Rosario ER, Ubeda OJ, Beech W, Gant DJ, et al. Betaamyloid oligomers induce phosphorylation of tau and inactivation of insulin receptor substrate via c-Jun $\mathrm{N}$-terminal kinase signaling: suppression by omega-3 fatty acids and curcumin. J Neurosci. 2009;29: 9078-89. doi:10.1523/JNEUROSCI.1071-09.2009.

39. Mattsson N, Olsson M, Gustavsson MK, Kosicek M, Malnar M, Månsson JE, et al. Amyloid- $\beta$ metabolism in Niemann-Pick C disease models and patients. Metab Brain Dis. 2012;27:573-85. doi:10.1007/s11011-012-9332-8.

40. Nakamura S, Nakayama H, Uetsuka K, Sasaki N, Uchida K, Goto N. Senile plaques in an aged two-humped (Bactrian) camel (Camelus bactrianus). Acta Neuropathol. 1995:90:415-8.

41. Oddo S, Caccamo A, Shepherd JD, Murphy MP, Golde TE, Kayed R, et al. Triple-transgenic model of Alzheimer's disease with plaques and tangles: intracellular Abeta and synaptic dysfunction. Neuron. 2003;39:409-21.

42. Oddo S, Caccamo A, Smith IF, Green KN, LaFerla FM. A dynamic relationship between intracellular and extracellular pools of Abeta. Am J Pathol. 2006:168:184-94.

43. Ono K, Condron MM, Teplow DB. Effects of the English (H6R) and Tottori (D7N) familial Alzheimer disease mutations on amyloid beta-protein assembly and toxicity. J Biol Chem. 2010;285:23186-97. doi:10.1074/jbc. M109.086496.

44. Rosen RF, Farberg AS, Gearing M, Dooyema J, Long PM, Anderson DC, et al. Tauopathy with paired helical filaments in an aged chimpanzee. J Comp Neurol. 2008;509:259-70. doi:10.1002/cne.21744.

45. Sahara N, Avila J. "Tau oligomers," what we know and what we don't know. Front Neurol. 2014:5:1. doi:10.3389/fneur.2014.00001.

46. Saito T, Matsuba Y, Mihira N, Takano J, Nilsson P, Itohara S, et al. Single App knock-in mouse models of Alzheimer's disease. Nat Neurosci. 2014; 17:661-3. doi:10.1038/nn.3697.

47. Selkoe DJ. Resolving controversies on the path to Alzheimer's therapeutics. Nat Med. 2011;17:1060-5. doi:10.1038/nm.2460

48. Selkoe DJ, Bell DS, Podlisny MB, Price DL, Cork LC. Conservation of brain amyloid proteins in aged mammals and humans with Alzheimer's disease. Science. 1987:235:873-7.

49. Serizawa S, Chambers JK, Une Y. Beta amyloid deposition and neurofibrillary tangles spontaneously occur in the brains of captive cheetahs (Acinonyx jubatus). Vet Pathol. 2012;49:304-12. doi:10.1177/0300985811410719

50. Siwak-Tapp CT, Head E, Muggenburg BA, Milgram NW, Cotman CW Region specific neuron loss in the aged canine hippocampus is reduced by enrichment. Neurobiol Aging. 2008;29:39-50.

51. Thal DR, Capetillo-Zarate E, Schultz C, Rüb U, Saido TC, Yamaguchi $H_{\text {, }}$ et al. Apolipoprotein E co-localizes with newly formed amyloid beta-protein (Abeta) deposits lacking immunoreactivity against $\mathrm{N}$-terminal epitopes of Abeta in a genotype-dependent manner. Acta Neuropathol. 2005;110:459-71.

52. Tokutake T, Kasuga K, Yajima R, Sekine Y, Tezuka T, Nishizawa M, et al. Hyperphosphorylation of Tau induced by naturally secreted amyloid- $\beta$ at nanomolar concentrations is modulated by insulin-dependent Akt-GSK3 $\beta$ signaling pathway. J Biol Chem. 2012:287:35222-33. doi:10.1074/jbc.M112.348300

53. Tomiyama T, Asano S, Furiya Y, Shirasawa T, Endo N, Mori H. Racemization of Asp23 residue affects the aggregation properties of Alzheimer amyloid beta protein analogues. J Biol Chem. 1994;269:10205-8.

54. Tomiyama T, Matsuyama S, Iso H, Umeda T, Takuma H, Ohnishi K, et al. A mouse model of amyloid beta oligomers: their contribution to synaptic alteration, abnormal tau phosphorylation, glial activation, and neuronal loss in vivo. J Neurosci. 2010;30:4845-56. doi:10.1523/ JNEUROSCI.5825-09.2010.

55. Tomiyama $T$, Nagata $T$, Shimada $H$, Teraoka R, Fukushima A, Kanemitsu $H$, et al. A new amyloid beta variant favoring oligomerization in Alzheimer's-type dementia. Ann Neurol. 2008:63:377-87. doi:10.1002/ana.21321.

56. Uchida K, Yoshino T, Yamaguchi R, Tateyama S, Kimoto Y, Nakayama H, et al. Senile plaques and other senile changes in the brain of an aged American black bear. Vet Pathol. 1995;32:412-4

57. Umeda T, Maekawa S, Kimura T, Takashima A, Tomiyama T, Mori H. Neurofibrillary tangle formation by introducing wild-type human 
tau into APP transgenic mice. Acta Neuropathol. 2014;127:685-98. doi:10.1007/s00401-014-1259-1.

58. Vite $\mathrm{CH}$, Head E. Aging in the canine and feline brain. Vet Clin North Am Small Anim Pract. 2014;44:1113-29. doi:10.1016/j.cvsm.2014.07.008

59. West MJ, Kawas CH, Stewart WF, Rudow GL, Troncoso JC. Hippocampal neurons in pre-clinical Alzheimer's disease. Neurobiol Aging. 2004;25:1205-12.

Submit your next manuscript to BioMed Central and we will help you at every step:

- We accept pre-submission inquiries

- Our selector tool helps you to find the most relevant journal

- We provide round the clock customer support

- Convenient online submission

- Thorough peer review

- Inclusion in PubMed and all major indexing services

- Maximum visibility for your research 